DOI 10.37882/2500-3682.2021.01.16

\title{
МАРКСИСТСКАЯ СОЦИАЛЬНАЯ ФИЛОСОФИЯ И ПРАВОВОЙ НИГИЛИЗМ: ОПЫТ КРИТИЧЕСКОГО ИССЛЕДОВАНИЯ
}

\section{LEGAL NIHILISM AND MARXIST SOCIAL PHILOSOPHY: A CRITICAL RESEARCH EXPERIENCE}

S. Sirin

Summary: The article is devoted to the study of legal nihilism as an object or field of influence from the Marxist philosophical worldview. The author proposes a concept according to which Marxist social philosophy (formerly historical materialism) is considered from the point of view of its negative impact on the legal life of a socialist society.

Keywords: socialist society, Marxist social philosophy, legal nihilism, subjectivism, voluntarism, jurisprudence.

\author{
Сирин Сергей Анатольевич \\ К.фр.н., дочент, Иркутский государственный \\ медицинский университет \\ tkocmina@gmail.com
}

Аннотация: Статья посвящена исследованию правового нигилизма как объекта или поля воздействия со стороны марксистского философского мировоззрения. Автором предложена концепция, согласно которой марксистская социальная философия (бывший исторический материализм) рассматривается под углом зрения ее негативного воздействия на правовую жизнь социалистического общества.

Ключевые слова: социалистическое общество, марксистская социальная философия, правовой нигилизм, субъективизм, волюнтаризм, юриспруденция.
$\mathrm{B}$ течение семи с половиной десятилетий общественное сознание советского общества формировалось и развивалось под непосредственным влиянием марксистско-ленинского философского мировоззрения. Марксистско-ленинская концепция природы, общества и человека оказывала прямое воздействие на все стороны общественной жизни советского общества, на все формы общественного сознания. Особенно глубокое воздействие со стороны марксистского философского учения испытывало правовое сознание советского общества, правовое сознание отдельных личностей.

Такое влияние марксистская философия оказывала благодаря своему особому положению в обществе. Никогда ранее, ни в одном обществе, ни одна философская система не занимала того абсолютно господствующего положения, которое приобрела марксистско-ленинская философия в СССР, а впоследствии в других социалистических странах. Фактически диалектический и исторический материализм получил статус непререкаемой, не подлежащей никакой критике идеологии, заменившей вследствие антирелигиозной политики партии и государства функции, принадлежащей прежде религии.

Впрочем, могучее влияние марксистско-ленинской философии на право и правовое сознание никогда никем не отрицалось, а наоборот, подчеркивалось как в философской, так и в юридической литературе. За годы советской власти написаны сотни книг, тысячи всевозможных брошюр и статей, посвященных методологической роли марксистской философии в понимании и развитии права и правового сознания. Трудно найти какую-либо работу по теории права, в которой бы не подчеркивалась мето- дологическая значимость марксистской философии для права. Однако во всей этой громадной литературе нет и следа критического анализа или даже просто критических замечаний о негативных последствиях слепого восхваления философских методологических принципов в изучении и применении права, в определении права в целом и отдельных юридических категорий.

Несмотря на безудержное восхваление методологической значимости марксистской философии для права и правового сознания, ее якобы благотворного и направляющего воздействия на все стороны правовой жизни общества, мы получили в результате горькие плоды массового правового нигилизма, разгул субъективизма и волюнтаризма, правовое бескультурье почти всех слоев советского общества.

Конечно, этот печальный итог правового «развития», а лучше сказать, правового нигилизма, нельзя объяснить однозначно. Он определяется множеством самых разнообразных причин, среди которых существенную, если не решающую роль, сыграли социально-философские установки марксизма-ленинизма, в соответствии с которыми создавались и принимались нормы права, формировалось соответствующее правовое сознание, осуществлялось правоприменение.

Разумеется, философская теория сама по себе не может оказать сколько-нибудь решительного воздействия на правовое состояние общества. Она становится действенной только в том случае, если возводится в ранг единственно правильной и научной, в ранг непреложных общеобязательных теоретических установок, как 
это и случилось в СССР. Мы попытаемся показать, что абсолютизация тех или иных философских концепций и их упрямое и огульное внедрение в правовую жизнь общества рано или поздно, но неотвратимо приводит к состоянию правового нигилизма, субъективизма и произвола. Другими словами, произвольное вмешательство в правовую жизнь на основе тех или иных философских и социально-политических построений, носящих уморительный характер, становится возможным лишь в том случае, если эти построения берутся на вооружение государством и, таким образом, получают государственную поддержку и приобретают преимущественное положение в сравнении с другими социально-политическими установками и философскими системами.

Всякое же произвольное вмешательство в социальную, в том числе правовую среду, не может не быть негативным. Это есть нарушение социальной экологии и поэтому не может не быть негативным. Оно обязательно влечет за собой всевозможные отрицательные последствия, в том числе приводит и к массовому правовому нигилизму.

Философская теория, не принимающая во внимание специфику правового развития тех или иных национальных государств, пытающаяся «внедриться» без учета исторического опыта правового развития тех или иных народов, неизбежно ведет к правовому нигилизму, к отрицанию правовых норм, которыми традиционно руководствовались на протяжении длительной истории эти народы и которые они готовы были безоговорочно выполнять, считая их «своими», или даже придавая им сакраментально-религиозный характер. Замена этих норм другими, составленными на основе философского мировоззрения и правового сознания отдельных «революционных» групп и начисто отрицающих предыдущий правовой опыт, как это и имело место в нашей стране, да и в некоторых других, так называемых социалистических странах, является одной из решающих причин формирования и развития правового нигилизма, субъективизма и волюнтаризма.

Было бы, конечно, несправедливо по отношению к любой философской теории, в том числе и к марксистско-ленинской, утверждать, что в ней нет ничего такого, что оказывается положительным в смысле воздействия на право, правовое воспитание и на правовую культуру. Бывший исторический материализм содержал немало ценных выводов и наблюдений, в том числе и по отношению к праву. Известно, что марксистско-ленинская социально-философская теория не отрицала известной значимости права и его влияния на ход исторического развития. Однако, в общем и целом, её оценка права носила скорее негативный характер.

Учитывая, что анализ положительных качеств марк- систской социально-философской теории, при всей его предвзятости и односторонности, был подробно сделан в многочисленных работах советских философов и юристов, вряд ли есть необходимость повторять общеизвестное. Что касается проблемы влияния марксистской социально-философской теории на правовое сознание социалистического общества, а тем более конкретного механизма такого воздействия, то фактически она представляет собой «terra incognito». Каких-либо работ на эту тему фактически не имеется.

Злободневность темы усиливается тем обстоятельством, что несмотря на предпринимаемые усилия со стороны новых властей России по устранению правового негативизма, в том числе, и в мировоззренческом плане, правовой нигилизм не только не ослабевает, а наоборот, усиливается, принимая угрожающий характер и облекаясь в новые, неизвестные до сих пор, формы своего проявления. Все это требует глубокого и срочного осмысления со стороны социальной науки и практики.

Возникающая ситуация сложилась под влиянием многих факторов, в том числе сохранившихся в своей основе прежних мировоззренческих, философских установок, а также возникших уже в новых условиях мировоззренческого плюрализма или даже просто мировоззренческого вакуума.

Поскольку влияние философии как определенной формы общественного сознания происходит, так сказать, на логико-идеологическом (методологическом) и социально-психологическом уровнях, в статье по необходимости соответственно рассматриваются оба аспекта воздействия марксистской социальной философии на сущность, содержание и формы правового нигилизма.

При этом сам правовой нигилизм как объект в данном случае философского методологического воздействия представляет собой не только, и даже не столько своеобразное юридическое явление, но сложное и во многом совершенно неизученное социально-психологическое явление, требующее социального анализа не только в узкой сфере права и с помощью соответствующих правовых приемов, но в более широком, именно, в философском плане, как феномен, проникающий во все поры общественной и государственной жизни. Поскольку нормы права регулируют всю общественную и частную жизнь людей, их отношение к природной и даже космической среде, постольку отрицательное, негативное отношение к праву - правовой нигилизм - захватывает в свою орбиту всю общественную жизнь, все сферы общества. Правовой нигилизм есть негативное отношение не только к праву вообще, а к экономической, хозяйственной деятельности, политике, семейным отношениям, $\mathrm{k}$ природе, и даже космосу. А это уже скорее общефилософская проблематика, чем узко правовая. 
Известно, что Маркс различал в праве две стороны, два аспекта: притязание субъекта права и социальную норму. Это различие Маркс последовательно проводит в «Критике Готской программы», утверждая, что, всякое право есть право неравенства. Природа права, замечает Маркс, заключается в применении одинакового и единого для всего масштаба. Но поскольку в действительности люди не равны, постольку право закрепляет фактическое неравенство.

«Право никогда не может быть выше, чем экономический строй и обусловленное им культурное развитие общества» [5] — вот вывод, который в очередной раз Маркс подчеркивает в работе «Критика Готской программы».

Поэтому нет ничего удивительного в том, что право и правовая наука в нашей стране, начиная с 1917 года, с момента установления советской власти, мягко говоря, недооценивались, а иногда и просто игнорировались. В 1922 году известный историк-марксист М.Н. Покровский сделал обзор достижений общественных наук за четыре послереволюционных года. [7] В этом сравнительно обширном обзоре «достижений» общественных наук для правовой науки места не нашлось, о ней фактически вообще ничего не упоминалось.

Необходимо заметить, что недооценка права, его роли в регулировании общественных отношений и процессов, права как общечеловеческого и национального культурного феномена вылилось фактически с самого начала советской, а лучше сказать, партийно-большевистской власти не только в отказе от наработанных веками правовых норм, но и в стремлении заменить их юридическими суррогатами. Принимаемые новые правовые акты отличались юридической безграмотностью, несовершенством формы, противоречивостью содержания, так как составлялись юридически некомпетентными людьми. Помимо всего прочего, многие из них были неграмотны в прямом смысле слова: тексты «напичканы» многочисленными ошибками, трудновыговариваемыми оборотами, отличались классовой пристрастностью, зачастую противоречили элементарным нормам общечеловеческой морали.

В самом первом декрете о суде (декрет №1), принятом 24 ноября 1917 года, ВЦИК РСФСР обязал все суды руководствоваться в своих решениях и приговорах старыми законами лишь постольку, поскольку они не противоречили так называемому революционному правосознанию и революционной совести.

Естественно, в этих условиях революционное правосознание и революционная совесть работали, что называется, на полную катушку. Что такое революционное правосознание, само собой разумеется, никто не знал. Под этой категорией скрывался какой-то магический таинственный смысл, известный только его носителям, тем, кто это так называемое революционное правосознание в себе воспитал, кто проникся революционными чувствами. И уж тем более «таинственным» являлось понятие «революционная совесть». Совесть - понятие, относящееся к сфере духа. Это весть, информация, которой владеют люди сообща, совместно и которая не может быть революционной или реформистской, пролетарской или буржуазной, таджикской или еврейской. Совесть - это нравственная, общечеловеческая категория и о ней можно судить лишь по степени интенсивности ее проявления.

Одной из примечательных особенностей советской правовой системы, вытекающей из общей философской концепции и правосознания социалистического общества, является своеобразная маскировка, потемкинские правовые деревни, видимость правового состояния общества, в. то время как фактически в обществе правит не закон, а принудительная сила отдельных социальных групп, осуществляющие свои особые субъективные цели. Такой вид права Гегель называл неправом. Неправо, по его мнению, «это такое право, которое в качестве особенного, и, следовательно, многообразного получает в противоположность в себе сущей всеобщности и простоте форму видимости». [2] Гегель различал три вида подобной видимости:

1. непреднамеренная,

2. обман,

3. преступление.

Все эти виды видимого права были широко распространены в нашей стране, как, впрочем, существуют и по сей день.

Учение марксизма о вторичности права по отношению к экономике опирается, как известно, на общее марксистское философское положение, согласно которому материя первична, а сознание вторично. Поскольку право есть категория субъективная, оно устанавливается субъективной волей людей, право обречено на вторичность и производность от экономических материальных отношений. Поскольку это положение самым тесным образом связано с общим вопросом о соотношении материального и идеального в обществе, мы позволим себе в самой общей форме высказать несколько замечаний относительного самого этого деления на материальное и идеальное в обществе.

Вся трудность этой проблемы заключается в том, что считать за материальное и идеальное, как разделить общественную жизнь на две противоположные стороны. Никто до Маркса не отваживался рассматривать вопрос о материальном и идеальном в обществе под этим углом зрения, справедливо полагая, что разделить общественные явления на материальные и идеальные ни практически, ни теоретически невозможно. 
Надо заметить, что отдельные стороны жизни общества, в том числе, и жизни в сфере права с помощью диалектического анализа Марксу и Энгельсу удалось объяснить вполне удовлетворительно и сделать на основе этого ряд ценных наблюдений и выводов. Особенно это касается марксистского анализа капиталистической экономики. И все же попытки Маркса найти материальную, экономическую отмычку для всех сложнейших проблем общественной жизни и в первую очередь права, стремление объяснить этот многогранный и тончайший феномен общества только с помощью экономических отношений оказались в целом несостоятельными.

В свете вышесказанного следует, на наш взгляд, отказаться от учения о вторичности права, его подчиненном, несамостоятельном статусе, якобы полностью зависящим от экономических отношений Отношение между экономикой и правом в принципе ничем не отличается от отношения права с другими сферами общественной жизни. Назначение права - регулировать взаимоотношения людей, упорядочивать общественные отношения как в сфере общественного бытия, так и в сфере общественного сознания. Право выполняет свои регулирующие функции и там, и здесь, в общем-то, одинаково. Было бы неверным рассматривать отношение права и экономики как какое-то особое отношение, которое определяет сущность и форму права в целом, в том числе его взаимоотношение с другими сферами общества.

Не случайно Ленин вопреки известному и основополагающему марксистскому принципу о первичности экономики и вторичности политики в 1922 году высказал сенсационное по тем временам положение о том, что в эпоху диктатуры пролетариата (то есть в исключительных условиях, в чрезвычайных обстоятельствах) политика не может не иметь первенства над экономикой. Но политика, любая политика предполагает определенные средства, с помощью которых она может быть реализована. И одним из таких решающих средств является право, без которого невозможны никакие социальные преобразования, а тем более коренная ломка прежних общественных отношений и создание новых. Так что, перефразируя это ленинское положение, можно с полным основанием сказать: в эпохи решительных действий, всякого рода преобразований, перестроек и социальных катаклизмов право не может не иметь первенства над экономикой. Более того, отдельные юристы даже полагают, что право всегда предшествует экономической деятельности, во всяком случае в условиях современного общества. Известный русский дореволюционный юрист профессор Ю.С. Гамбаров пришел к выводу, что невозможно вообще представить появление того или иного экономического явления, например, частной собственности, без определяющей его юридической предпосылки. «Ни свобода личности, ни овладение, ни завоевание, ни труд не ведут к собственности иначе, как при согласии на это - по крайней мере молчаливом - государственной власти. Вне государства или какого-нибудь иного принудительного правового общения не может быть никакой собственности, так как право невозможно без иска, иск - без исполнения и исполнения - без принуждающей к нему власти. «Собственность и закон, - говорил Бента, - родились вместе и умрут вместе. До закона не было собственности; устраните закон, и собственность перестанет существовать» - «Удержание земли, - писал Лабулэ, - есть только факт, утверждаемый силой, пока общество не берет на себя защиту этого факта, освящая его своей санкцией: с этих пор факт делается правом, и это право есть собственность». В этом смысле государство создает собственность, как оно создает и все другие юридические отношения». [1]

Марксистская философская концепция вторичности права, его ненадобности в будущем коммунистическом обществе, абсолютизация экономических отношений, как единственного определяющего фактора правосознания, права и правовых отношений вкупе с другими причинами способствовала махровому расцвету правового нигилизма, наплевательскому отношению к праву прежде всего со стороны властей, а вслед за ними и всей массы населения страны. Это теоретическое положение сыграло роковую роль в формировании нездорового правового сознания в обществе.

Во-первых, оно как бы оправдывало негативное отношение к праву, факты произвола и беззакония, подводя под них «научную» базу.

Во-вторых, это теоретическое положение сбивало с толку всю правовую науку, направляя ее изыскания, исследования и научные поиски по ложному пути, в неверном направлении, провоцируя на фальшивые положения и выводы. Все это наносило и науке, и особенно практике, непоправимый вред. Правовое сознание и правовая культура общества формировались односторонне и предвзято.

Между тем, правильное понимание соотношения права, морали и религии не менее существенно для формирования верного взгляда на право и его действительную значимость, нежели установление истинных механизмов взаимоотношения права и экономики.

На наш взгляд, массовое распространение правового нигилизма объясняется, помимо всего прочего, ложными теоретическими посылками о связи права с моралью, а уж тем более, с религией.

Мораль играет особую, можно сказать, решающую роль в возникновении и формировании правильного, «здорового» правового сознания. Если законы и право в целом не содержат в качестве главного своего ориен- 
тира достижение какой-либо моральной цели: соблюдение справедливости, правды, добра, уменьшения и пресечения зла, то такое право и такие законы неизбежно будут вызывать негативное к ним отношение со стороны большинства граждан, то есть тех, кому они, эти законы, непосредственно адресованы.

В свою очередь, право и законы должны применяться в идеале в условиях живого, морально укорененного правосознания. Моральные принципы и нормы должны лежать в основании права, выступать его целью. Содержание многих правовых норм фактически является своеобразной конкретизацией моральных установлений и принципов, общих моральных требований в юридических предписаниях, запретах и санкциях.

Таким образом, право, во всяком случае многие его нормы, определяются не экономическими отношениями и экономической деятельностью, но моральными принципами и предписаниями. Замечательный русский юрист и государственный деятель прошлого столетия Сперанский, говоря о соотношении права и морали (права и правды, по его терминологии), отмечал: «Всякое право, а следовательно, и русское право, постольку есть право, поскольку основано на правде. Там, где кончается правда и где начинается неправда, кончается право и начинается самовластие» [4]

Не менее тесно, чем с экономикой и с нравственностью, право связано с религией, с религиозным сознанием. Связь права с религией не носит столь зримый и очевидный характер, который мы наблюдаем в отношениях права с экономическим и нравственным сознанием. Эта связь, скорее духовная, она не относится непосредственно к предмету механизма регулирования человеческих отношений.

Правосознание тысячами невидимых духовных нитей связано с религиозными началами человека, оно питается этой духовной пищей и когда по каким-либо причинам лишается ее, становится хилым, больным, уродливым и извращенным. «Нет человека без правосознания, - пишет по этому поводу замечательный русский философ и юрист И.А. Ильин, - но есть множество людей с пренебреженным, запущенным, уродливым или даже одичавшим правосознанием. Этот духовный орган необходим человеку, он участвует так или иначе во всей его жизни, даже и тогда, когда человек совершает преступление и притесняет соседей, предает свою родину и т.д., ибо слабое, уродливое, продажное, рабское, преступное правосознание остается правосознанием, хотя его душевно-духовное строение оказывается неверным, а его содержание и мотивы - ложными или дурными". [3]

Наш семидесятилетний опыт богоборческой деятельности, активного, жесткого и жестокого вытравливания религиозного начала из сферы права, правосознания и правовых отношений подтвердил ту непреложную истину, что разрыв права с религиозными источниками духовной жизни приводит к массовому заражению общества бациллами правового нигилизма, жестокости и беззакония. Теряется вера, исчезает любовь, милосердие, совесть, чувство справедливости. Правовой нигилизм, так широко распространенный в нашем обществе, напрямую связан с нигилизмом религиозным, с борьбой против религии, с атеистической деятельностью государства, его органов, правящей коммунистической партии.

Марксистское учение о вторичности права, его полной зависимости от экономических отношений, с одной стороны, оказалось несостоятельным в научном плане со всеми вытекающими отсюда последствиями, а с другой, оказало губительное воздействие на характер отношения к праву, формирование искаженного правового сознания масс, что и создало благодатную почву для процветания массового правового нигилизма. Наконец, учение о вторичности права и его полной зависимости от материальных экономических отношений увело в сторону внимание исследователей, а также широкой общественности от изучения и учета действительных и важнейших связей права, правового сознания с другими формами общественного сознания и в первую очередь с моралью и религией, что опять-таки способствовало развитию и распространению правового нигилизма в нашей стране.

\section{ЛИТЕРАТУРА}

1. Гамбаров Ю.С. Право собственности. - В кн.: Русская Высшая школа в Париже. Спб, 1905.с. 493.

2. Гегель Г. Философия права. М., 1990, с.138

3. Ильин И.А. Путь к очевидности. М., 1993, с.251.

4. Коркунов Н.М. Русское государственное право, т.1. Спб, 1901, с. 205.

5. Маркс К. Критика Готской программы. Соч., т.4.с. 38.

6. Покровский М.Н. Общественные науки в России за четыре года (1917-1921). - В кн.: Наука в Советской России. М., 1992, с. 34. 